\title{
HYPER-TEMPORAL REMOTE SENSING FOR SCALING BETWEEN SPECTRAL INDICES AND FLUX TOWER MEASUREMENTS
}

\author{
KiA, S. H. ${ }^{1 *-M i L T O N, ~ E . ~ J . ~}{ }^{1}$ \\ ${ }^{1}$ Geography and Environment, University of Southampton \\ University Road, Southampton, SO17 1BJ, United Kingdom \\ *Corresponding author \\ e-mail:shk1g09@soton.ac.uk and shkia52@gmail.com \\ (Received 25 $5^{\text {th }}$ Jul 2014; accepted $2^{\text {nd }}$ Sep 2014)
}

\begin{abstract}
Quantifying spatial and temporal variations of the environmental variables is a significant challenge in the Earth's System studies. This can be addressed by tracking the exchange rate of carbon between land surface and the atmosphere through an effective integration of the tower-based flux measurements and remote sensing observations. However, confidence of these data with regard to extending into ecosystem or regional scales remains uncertain, particularly in heterogeneous landscapes. This paper studies how data with the necessary spatial and temporal sampling may be obtained for a typical temperate forest in southern England. A time series of the inter-calibrated Normalized Difference Vegetation Index (NDVI) from the Disaster Monitoring Constellation (DMC) over the flux tower extent suggested that the spatial variability of the canopy changed significantly during transitions from leaf-off to leaf-on conditions because of canopy patchiness at high spatial resolution, scales finer than a coarse satellite-sensor pixel. The availability of three acquisitions within five days during early March provided the opportunity to look at the sensitivity of the NDVI to extraneous factors, which showed the uncertainty in this spectral index to vary with the flux footprint coverage, peaking at around 5\% early in the season. This is comparable to the error that could be introduced by uncertainty in atmospheric correction specifically the parameterisation of aerosols. Thus, in the case of Wytham Woods, it may be more important to improve the representation of aerosols in the atmospheric model used than replace the generalised flux tower extent with a realistic flux footprint.
\end{abstract}

Keywords: Disaster Monitoring Constellation (DMC), Flux Footprint Coverage, Spatial and Temporal Sampling, Spectral Index

\section{Introduction}

Understanding the Earth's system dynamics and quantifying spatial and temporal variations of factors that influence environmental change will provide decision makers with the best information to manage and protect vital ecosystem services. This will improve our ability to mitigate the effects of environmental change. In this aspect, one of the primary challenges is accurate measurement of the key environmental variables. In spite of great advances in in-situ instrumentation, measuring environmental variables at appropriate temporal and spatial scales remains as a significant challenge in ecosystem studies.

Since the late 1980's the eddy covariance (EC) technique has been used to measure the exchanges of various gases (i.e. carbon dioxide; water vapour; and methane) and energy between land surface and the atmosphere for a variety of applications, such as ecosystem productivity, carbon budget and sequestration, as well as landfill emissions and urban flux (Burba and Anderson, 2010). The EC technique is based on the turbulent flow theory in the atmospheric boundary layer and used to measure scalar fluxes from the covariance between the vertical wind speed and the gas concentration averaged 
across a particular spatial scale in the upwind direction, referred to as flux footprint, and over a particular time interval typically a period of 30 minutes (Baldocchi et al., 2001, Burba and Anderson, 2010). This technique is the most widely used accurate and direct method to measure the exchange rate of carbon dioxide $\left(\mathrm{CO}_{2}\right)$ between terrestrial ecosystems and the atmosphere, also known as $\mathrm{CO}_{2}$ flux.

The flux footprint coverage represents an upwind surface where measured fluxes are registered by the instruments. Figure 1 depicts general concept of flux footprint. In this figure the darker red colour shows the more contribution that is coming from the surface area certain distance away from the eddy covariance system. The size and shape of the footprint coverage is a dynamic area depending on three main factors including: measurement height; surface roughness; and meteorological conditions such as atmospheric thermal stability condition, wind speed and direction (Baldocchi et al., 2001).

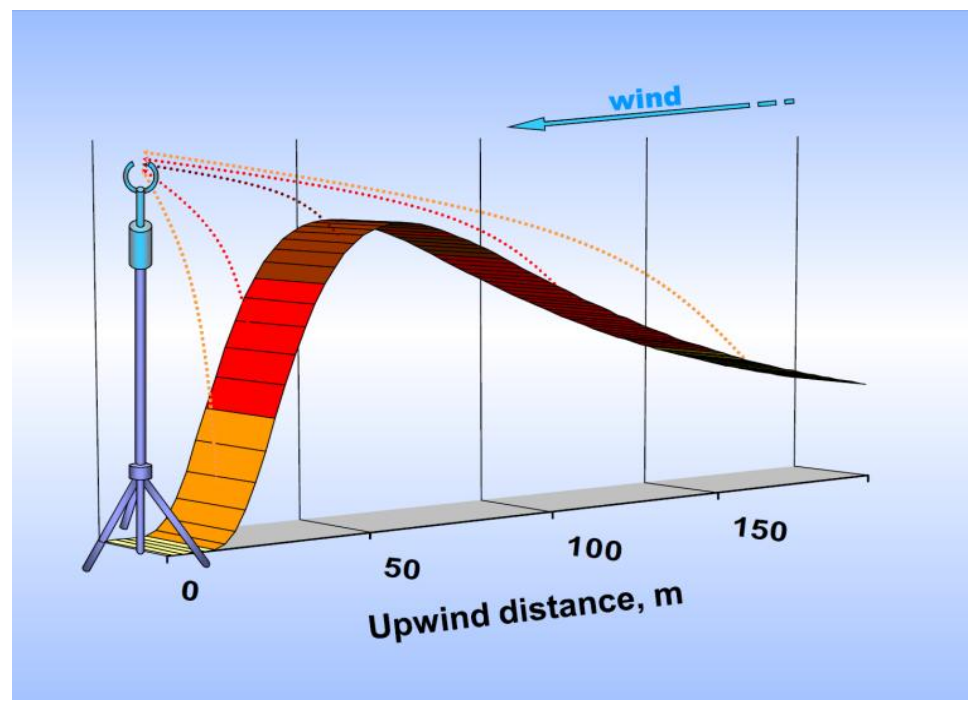

Figure1. General concept of flux footprint (Burba and Anderson, 2010)

Quantification of the exchange rate of $\mathrm{CO}_{2}$ across a wide range of spatial and temporal scales requires that tower-specific EC flux measurements to be extended using Earth Observation (EO) data and remote sensing techniques (Baozhang Chen et al., 2009, B. Chen et al., 2009, Chen et al., 2008, Kim et al., 2006, Xiao et al., 2012, Xiao et al., 2011). Despite the success of EC technique, confidence of these data with regard to extending into ecosystem or regional levels remains uncertain, particularly in heterogeneous landscapes (Kim et al., 2006, Xiao et al., 2012). The most important errors and issues associated with the EC technique are dependent on its intrinsic assumptions as follows:

- Flux measurements are made at only a few points;

- Flux measurements are restricted to periods when the atmosphere conditions are steady;

- Flux towers are installed across relatively homogeneous locations, while landscape heterogeneity is considerable;

- The location of flux tower sites has to be relatively flat; 
- Flux measurements are associated with uniform footprint of vegetation upwind; and

- The sensors and the data-logging system are able to sense and record the fastest and smallest eddies (Baldocchi, 2008, Baldocchi et al., 2001, Burba and Anderson, 2010).

Unfortunately, very few natural ecosystems meet these strict criteria. In reality, many natural and semi-natural ecosystems are situated in and among complex landscapes with varying atmospheric conditions (Forman, 1995, Forman and Godron, 1986, Frohn, 1998, Turner et al., 2002).

\section{Theoretical Background}

In terrestrial ecosystems, in general, the exchange rate of $\mathrm{CO}_{2}$ is mainly controlled by the photosynthesis-respiration process. Thus, ecosystem productivity and its dynamics can be studied by measuring the $\mathrm{CO}_{2}$ fluxes, a process that is referred to as Net Ecosystem Exchange (NEE) (Lambers et al., 2008, Monteith, 1972). To quantify the ecosystem productivity it is convenient to track $\mathrm{CO}_{2}$ uptake from the atmosphere over various spatial and temporal scales (Prentice et al., 2000, Xiao et al., 2012) using Earth Observation (EO) data and Remote Sensing (RS) techniques. Most applications of remote sensing in ecological studies derive from the ability to detect spectral features associated with the photosynthetic process, which can then be used for spatially explicit models of photosynthesis capacity and efficiency. Gross Primary Production (GPP) and Net Primary Production (NPP) takes into account the uptake of $\mathrm{CO}_{2}$ by vegetation during photosynthesis and its release during autotrophic respiration, respectively. In this aspect, the MOD17 GPP/NPP model is the first continuous satellite-driven dataset monitoring global vegetation productivity at $1-\mathrm{km}$ spatial resolution (Running et al., 2000, Running et al., 2004). However, these data require appropriate algorithms for scaling and interfacing eddy covariance flux measurements (Baozhang Chen et al., 2009).

There is a robust theory for the relationship between surface reflectance of incident radiation and the process model for modelling vegetation productivity based on the concept of Light Use Efficiency (LUE) (Monteith, 1972). This expresses GPP as function of the absorbed photo-synthetically active radiation (fAPAR) between 400-700 $\mathrm{nm}$ wavelengths and the efficiency of photosynthesis process (Sellers et al., 1992). Monteith (1972) defined the photosynthesis efficiency term as the ratio of energy stored in formation of carbohydrates to APAR, which generates the LUE logic for estimating GPP from EO data. The LUE model, rather than describing complex biochemical, meteorological and canopy structure information, attempts to describe the overall ability of canopies or ecosystems to convert incident energy into biomass. The fAPAR implies to the fraction of the incoming solar radiation in the photo-synthetically active radiation (PAR) spectral region, which is converted into biomass by a photosynthesising organism (Sellers et al., 1992). Therefore, the basic LUE model describes GPP in terms of APAR, here referred to photosynthesis capacity, and photosynthetic efficiency as:

$$
G P P=\downarrow P A R \times f A P A R \times \varepsilon
$$


where " $f A P A R^{\|}$represents the fraction of " $P A R^{\mathrm{w}}$ absorbed by vegetation, and " $\varepsilon$ " refers to realised LUE or the efficiency of converting $f A P A R$ into fixed carbon, (Monteith, 1972, Sellers et al., 1992, Running et al., 2000, Running et al., 2004, Hilker et al., 2008). The photosynthesis efficiency may be influenced by environmental constraints, the scalars that attenuate maximum efficiency of photosynthesis process, including air temperature and availability water as:

$$
\varepsilon=\varepsilon_{\max } \times T \times V P D
$$

where " $\varepsilon_{\max }{ }^{"}$ is biome-specific maximum efficiency of photosynthesis process, " $T$ " refers to the daily temperature, and " $V P D^{n}$ is the daylight average vapour pressure deficit. For example, high VPD have been shown to induce stomata closure in many species, while low temperatures inhibit photosynthesis process. These scalars, as illustrated in Figure 2, vary linearly between 0 and 1 as a consequence of suboptimal temperature and water availability for photosynthesis process.
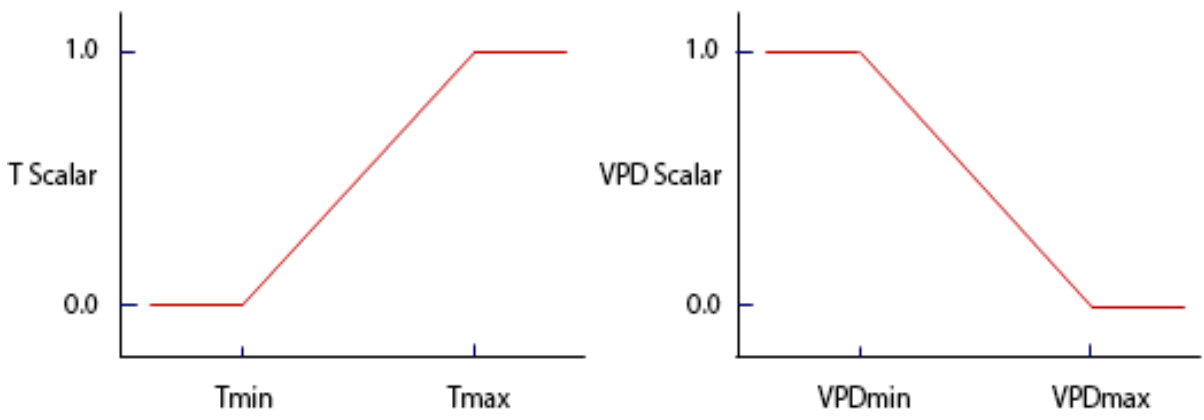

Figure 2. The T and VPD attenuation scalars are simple ramp functions of daily temperature and water availability

The LUE model parameters can be determined remotely using both empirical models relying on curve fitting of canopy reflectance measurements and physical models based on a canopy reflectance model. The empirical approaches are based on spectral vegetation indices (VI), which employ discrete spectral wavelengths. Various relationships between $f$ APAR and spectral VI have been investigated for different vegetation types across a range of spatial and temporal scales (Gamon et al., 1990, Gamon et al., 1995, Glenn et al., 2008, Hilker et al., 2008, Nakaji et al., 2007, Sellers et al., 1992, Wylie et al., 2003).

Alternatively, many studies have demonstrated retrieval models for scaling between the $\mathrm{CO}_{2}$ flux estimates derived from either airborne- or satellite-based spectral indices or those derived directly from tower-based EC measurements at the local scale, implying that the land surface is homogeneous. They also revealed the critical importance of the spatial domain, both in terms of the pixel size and the extent of the image. A further consideration is the temporal domain, as the basis of tower-based EC 
measurements involves a change over time. Accurate measurement and understanding of processes implies repeated remote sensing measurements, both over a few days (e.g. to study short-term changes in photosynthesis) and over a growing season (e.g. carbon source/sink studies). However, these studies have taken at best an empirical approach to characterising the difference in spatial scale between a given platform-sensor and the real flux tower footprint, and did not explicitly take into account the difference in sampling supports. This paper investigates how data with the necessary spatial and temporal sampling may be obtained for a temperate mixed forest, which is typical of many woodland areas throughout the northern hemisphere. The first thing that is apparent is that data from the MODIS sensor are not ideal for this task. First, its spatial resolution is too coarse for most areas of woodland, which are spatially variable. Second, the temporal sampling of the MODIS VI product is more irregular and less predictable than it first appears. Although this generally results in a smooth VI curve for the year as a whole it presents difficulties when trying to compare the MODIS product with a specific event, such as an overpass of another sensing system or a measurement from a flux tower.

The alternative approach investigated in this research was to identify a remote sensing system that offered a relevant spectral capability, but had more frequent and predictable sampling and finer spatial resolution. The requirement for this to be available globally excludes aircraft and other local solutions. Therefore, the objectives of the research described in this paper were:

- To obtain as many DMC and MODIS images of the study site as possible during one growing period (early Spring to mid-Summer), and to inter-calibrate them so they would be suitable for measuring change in NDVI during the year;

- To determine the repeatability of DMC NDVI measurements over a period of a few days;

- To investigate whether differences in the size and shape of the flux footprint (e.g. whether it is generalised or realistic) would significantly affect DMC NDVI values, and whether this result varied during the growing season; and

- To assess the pros and cons of DMC data as a means of mapping and monitoring ecological changes in woodlands in typical temperate forest.

Precise definition of the flux footprint was not an issue when working with MODIS data as the pixel size was so large, but, as Figure 3 shows, DMC data have much higher spatial resolution, so internal spatial variation within the woodland had to be considered.

\section{Methodology}

\section{Site Description}

At present, over 500 active flux tower sites are operated on a long-term and continuous basis throughout the world (Fluxnet, 2013). These monitor the net exchange of $\mathrm{CO}_{2}$, water vapour and energy flux in a variety of ecosystems, including deciduous broadleaf forest, coniferous forest, grassland and cultivated cropland. Among these sites, Wytham Woods, one of the UK Environmental Change Network's (ECN) terrestrial sites was selected due to the availability of high quality ecological data, eddy covariance flux measurements, and EO data sets. Wytham Woods is a temperate 
broadleaf forest located in the upper Thames basin, $5 \mathrm{~km}$ north-west of Oxford in southern England (Lat: 51.77 N; Lon: -1.33 E).

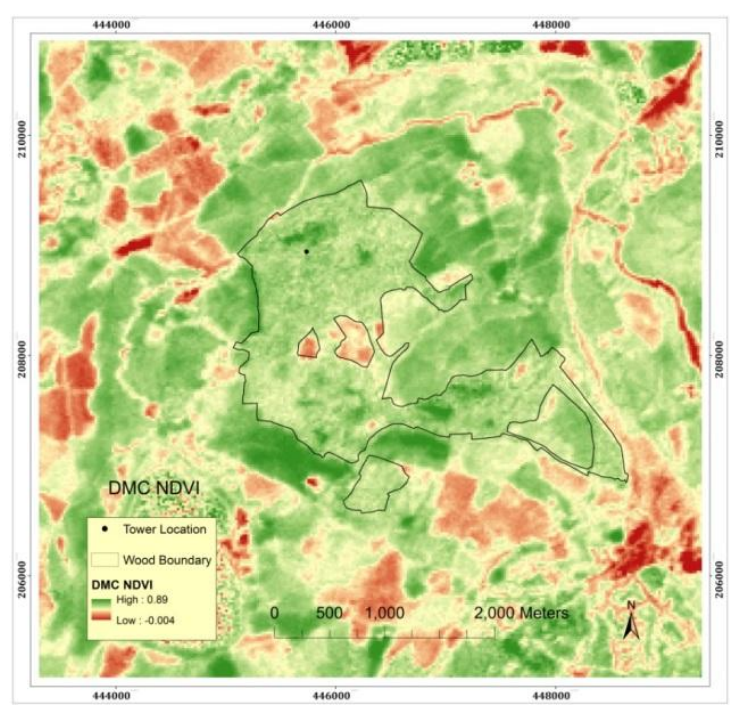

DMC NDVI on $2^{\text {nd }}$ March 2010 (Julian Day: 62)

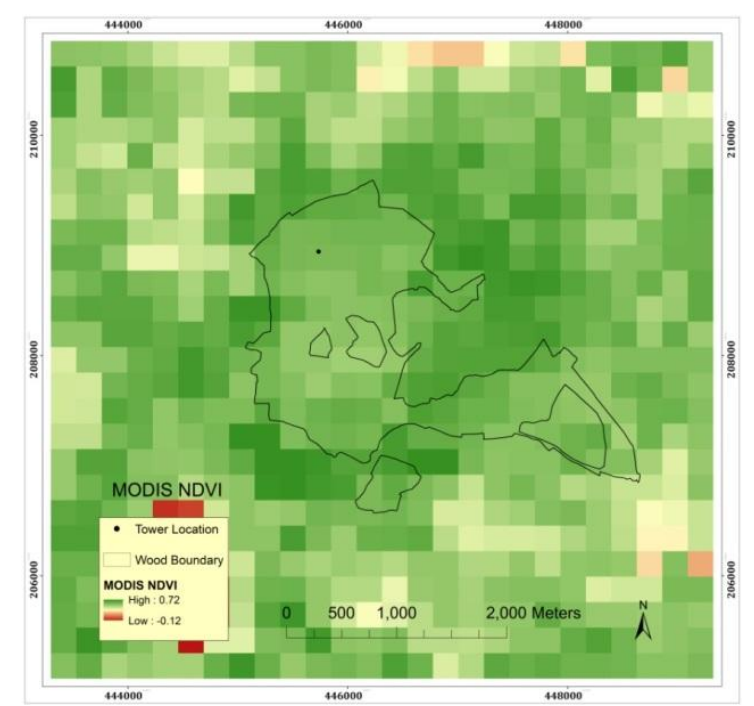

MODIS NDVI over $18^{\text {th }}$ Feb. - $5^{\text {th }}$ March 2010 (Julian Day: 49 - 65)

Figure 3. Comparing spatial resolution of satellite sensor systems: (a) DMC NDVI with $22 \mathrm{~m}$ spatial resolution; and (b) MODIS NDVI with $250 \mathrm{~m}$ spatial resolution

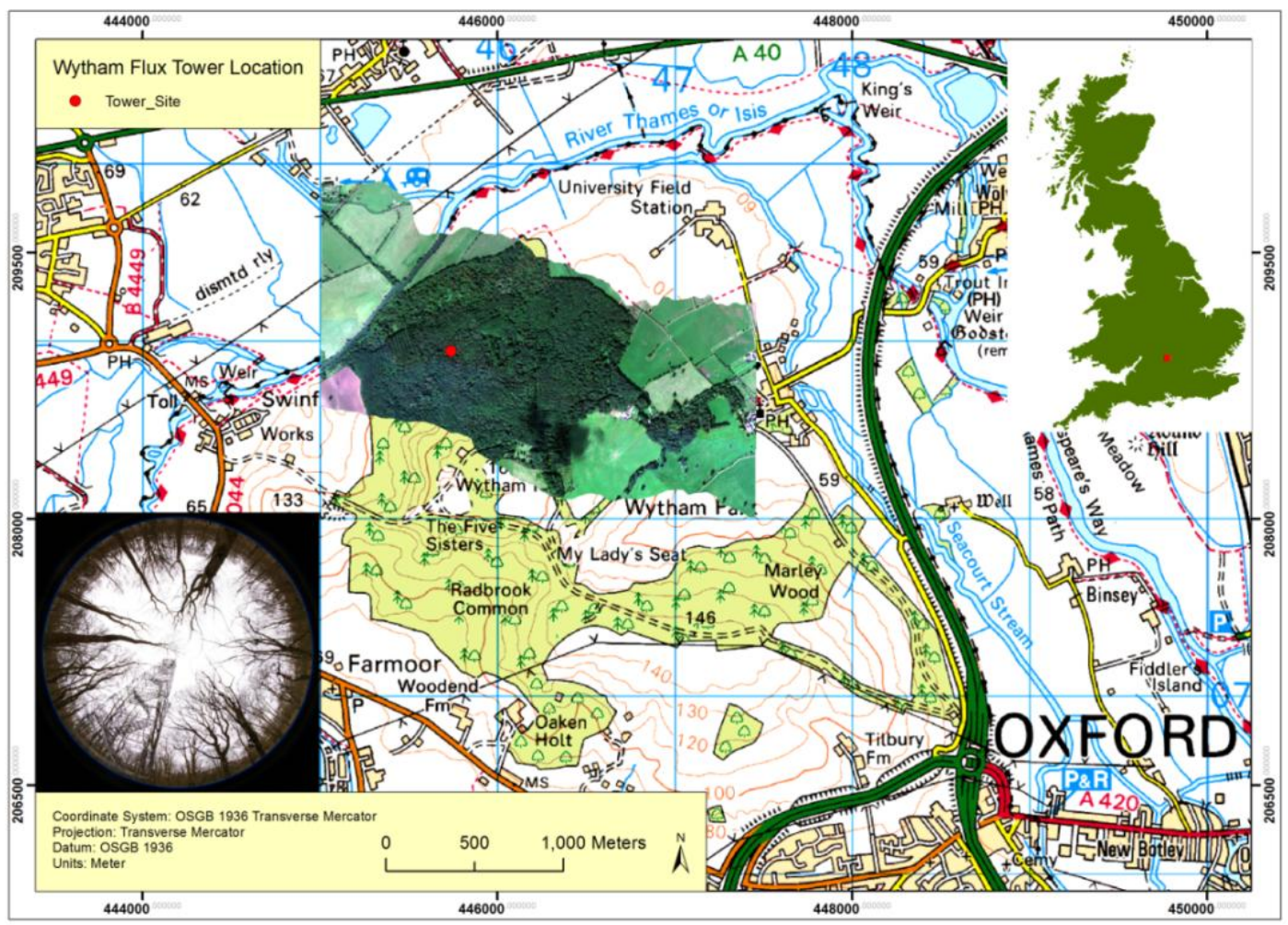

Figure 4. Location of the Study Site, Wytham Woods, Oxfordshire-UK; overlaid on a true colour composite of airborne hyperspectral imagery (NERC-ARSF Eagle data), and OS 1:50,000 Colour Raster SP40 (Adapted from Ordnance Survey DigiMap, 2010 and NERC$A R S F, 2009)$ 
The site contains a $25 \mathrm{~m}$ high micrometeorological flux tower where eddy covariance measurements of turbulent fluxes have been continuously recorded since May 2007 (Thomas et al., 2010). Wytham's EC instruments include a 3D sonic anemometer measuring wind vector components and an open-path gas analyser (LI-COR 7500) measuring atmospheric $\mathrm{CO}_{2} / \mathrm{H}_{2} \mathrm{O}$ fluxes. Wytham Woods is comprised of ancient, secondary and plantation woodlands (i.e. mixed forest of $400 \mathrm{ha}$ ) with four main elements forming a landscape mosaic including deciduous forest; patches of seminatural grassland and scrub; cultivated cropland; and some small wetland areas, i.e. whole site of 770 ha (Uk-Ecn, 2012). The flux tower system, as illustrated in Figure 4, is located on the north slope of a hill surrounded by mixed forest that includes scrub, non-coniferous and coniferous trees for approximately $450 \mathrm{~m}$ to the north and approximately $1000 \mathrm{~m}$ to the east and the south-west. The altitude ranges from $60 \mathrm{~m}$ above sea level on the river floodplain to $165 \mathrm{~m}$ at the top of Wytham Hill. Meteorology data from the UK Environmental Change Network (ECN) Wytham site have been recorded by Automatic Weather Station since 1992 (Savill et al., 2010). The climate is typical of central England, with the mean annual temperature and precipitation approximately $10.0^{\circ} \mathrm{C}$ and $720 \mathrm{~mm}$, respectively. According to the National Vegetation Classification (Rodwell, 1991), both ancient and secondary woodlands are part of community W8, Fraxinus excelsior - Acer campestre - Mercurialis perennis woodland, the most prominent species being ash (Fraxinus excelsior), field mapel (Acer campestre), and hazel (Corylus avellana), as well as sub-dominant species oak (Quercus robur) and sycamore (Acer pseudoplatanus).

\section{Pre-processing the Satellite Sensor Data}

A total of eight Disaster Monitoring Constellation (DMC) images were acquired between March and the end of June 2010 (Table 1 and Figure 5), confirming the power of the constellation approach to obtain frequent observations, even when faced with intermittent cloud cover. During this same period NASA acquired seven MODIS products of the same area, although of course, with much coarser spatial resolution (250 m compared with $22 \mathrm{~m}$ or $32 \mathrm{~m}$ ).

Table 1. DMC data sets acquired during 2010

\begin{tabular}{cccccc}
\hline $\begin{array}{c}\text { Imaging Date } \\
(\mathrm{dd} / \mathrm{mm} / \text { yyyy })\end{array}$ & $\begin{array}{c}\text { Imaging Time } \\
(\mathrm{UT})\end{array}$ & Mission & $\begin{array}{c}\text { Pixel } \\
\text { Size }(\mathrm{m})\end{array}$ & $\begin{array}{c}\text { Image } \\
\text { Clarity }\end{array}$ & $\begin{array}{c}\text { Viewing } \\
\text { Angle }\end{array}$ \\
\hline $02 / 03 / 2010$ & $09: 43: 21$ & UK-DMC2 & 22 & Clear & 28.74 \\
$05 / 03 / 2010$ & $09: 46: 39$ & UK-DMC2 & 22 & Clear & 22.06 \\
$07 / 03 / 2010$ & $09: 54: 31$ & DEIMOS & 22 & Clear & 5.47 \\
$20 / 04 / 2010$ & $08: 03: 51$ & UK-DMC & 32 & Clear & 0.82 \\
$27 / 04 / 2010$ & $10: 08: 21$ & UK-DMC2 & 22 & Clear & 20.48 \\
$23 / 05 / 2010$ & $09: 52: 10$ & UK-DMC2 & 22 & Clear & 17.85 \\
$04 / 06 / 2010$ & $09: 56: 34$ & UK-DMC2 & 22 & Clear & 25.82 \\
$16 / 06 / 2010$ & $09: 52: 02$ & UK-DMC2 & 22 & Cloudy & 27.46 \\
\hline
\end{tabular}

The DMC data sets were supplied projected to UTM/WGS84 (Level 1T), so they were re-projected into British National Grid (BNG), Datum OSGB36 and subsets 
produced over the extent of Wytham Woods $(600 \times 600$ pixels $)$. Image registration was performed by using 20 ground control points identified on Ordnance Survey MasterMap and using polynomial, nearest-neighbour resampling. The RMS errors were less than 0.75 pixels. Furthermore, time-series images from MOD13Q1 were geometrically registered to the same coordinate system as DMC data sets. All the satellite sensor data were corrected for the effect of the atmosphere. The MODIS data had been converted to reflectance and adjusted to nadir angle as part of the MODIS processing chain prior to the calculation of the NDVI (Masuoka et al., 2011).

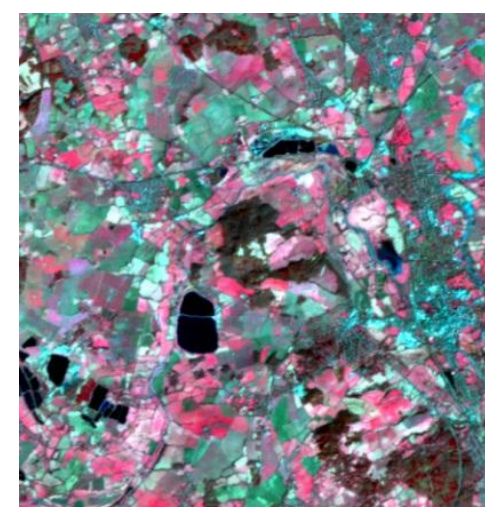

$2^{\text {nd }}$ March, NASR

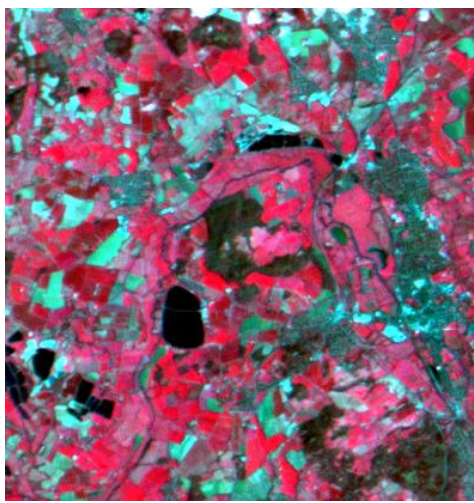

$20^{\text {th }}$ April, NASR

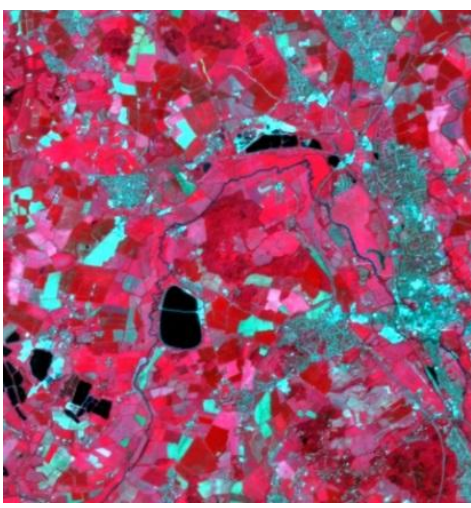

$4^{\text {th }}$ June, NASR

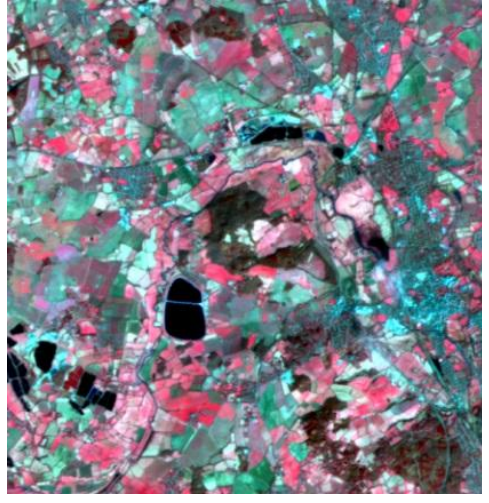

$5^{\text {th }}$ March, NASR

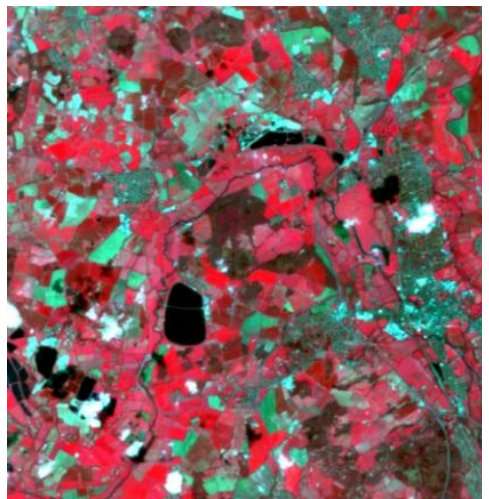

$27^{\text {th }}$ April, NASR

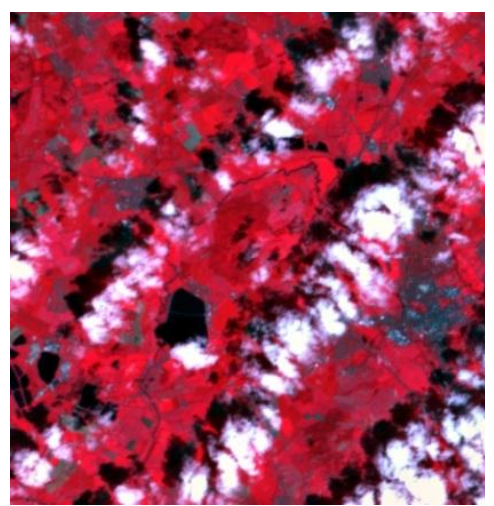

$16^{\text {th }}$ June, NASR

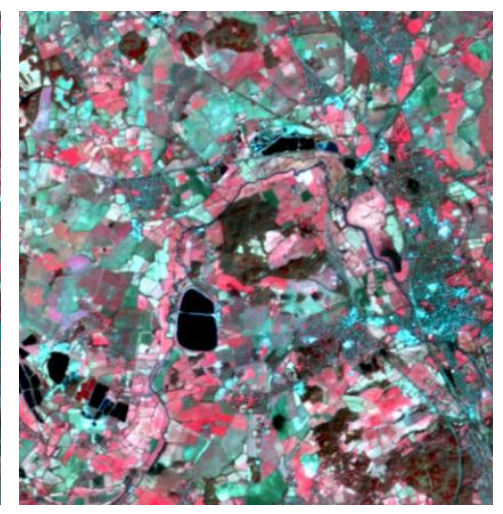

$7^{\text {th }}$ March, NASR

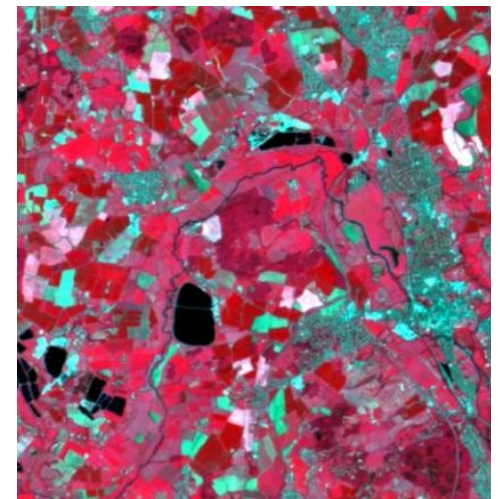

$23^{\text {rd }}$ May, NASR

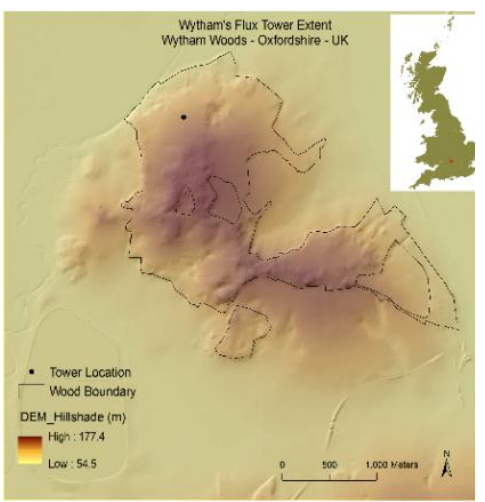

Wytham Woods

Figure 5. Time series of normalized absolute calibrated reflectance DMC images over Wytham Woods for the 2010 growing season 
The DMC data were first converted to radiance at the top of atmosphere (TOA) using the bias and gain values specified by data provider. They divided naturally into three phases based on the date of acquisition. The first three images were acquired within the first week of March, when many of the trees were still bare. The next two images came from a week in late April when the tree canopy was rapidly developing, and the final three images were acquired between $23^{\text {rd }}$ May and $16^{\text {th }}$ June, when the tree canopy was almost fully developed. The DMC data were atmospherically corrected using the ATCOR-2 program (Richter, 2011), using a standard mid-latitude atmosphere and typical values of water vapour and aerosol type. The results of this showed an apparent change in reflectance during the period $2^{\text {nd }}$ to $7^{\text {th }}$ March (Table 2), when none would have been expected, which suggested that uncertainty in the parameters of the radiative transfer model was having an effect. To overcome this, a method of image normalisation was applied in which the image closest to nadir view angle (and visually the clearest) for each phase (the reference image) was corrected to reflectance using ATCOR-2 and then the other images from the same phase were normalised to the reference image using the method of iteratively reweighted radiometric normalisation (IR-MAD) (Canty and Nielsen, 2008). This technique automatically found spectrally invariant targets within a series of related images and adjusted the target images to match the designated reference image by applying a linear transformation to the data. After applying this hybrid ATCOR/IR-MAD technique, the three DMC images from March showed no significant change in reflectance in either Red or NIR wavebands (Table 3).

Table 2. Red and Near-Infrared wavebands behavior over early growing season after absolute atmospheric correction (surface reflectance) across Wytham flux tower extent

\begin{tabular}{|c|c|c|c|c|c|c|c|c|}
\hline \multirow{2}{*}{$\begin{array}{l}\text { Acquisition } \\
\text { Date }\end{array}$} & \multicolumn{4}{|c|}{ Red Waveband Derived from ATCOR } & \multicolumn{4}{|c|}{ NIR Waveband Derived from ATCOR } \\
\hline & Mean & Median & $\mathrm{SD}$ & $\mathrm{CV}$ & Mean & Median & $\mathrm{SD}$ & $\mathrm{CV}$ \\
\hline $2^{\text {nd }}$ March & 6.05 & 6.00 & 1.34 & 22.15 & 27.87 & 27.50 & 3.24 & 11.63 \\
\hline $5^{\text {th }}$ March & 8.17 & 8.00 & 1.15 & 14.01 & 31.16 & 31.00 & 2.98 & 9.57 \\
\hline $7^{\text {th }}$ March & 6.34 & 6.00 & 1.15 & 18.07 & 27.74 & 27.00 & 3.05 & 10.98 \\
\hline $20^{\text {th }}$ April & 6.07 & 6.00 & 0.97 & 15.90 & 38.25 & 38.00 & 4.45 & 11.62 \\
\hline $27^{\text {th }}$ April & 5.66 & 5.50 & 0.98 & 17.23 & 48.58 & 47.50 & 6.48 & 13.34 \\
\hline $23^{\text {rd }}$ May & 4.00 & 4.00 & 0.68 & 16.90 & 77.05 & 77.00 & 5.82 & 7.55 \\
\hline $4^{\text {th }}$ June & 3.55 & 3.50 & 0.49 & 13.82 & 80.37 & 80.50 & 6.01 & 7.48 \\
\hline $16^{\text {th }}$ June & 4.73 & 4.50 & 0.71 & 15.03 & 83.66 & 85.00 & 7.98 & 9.53 \\
\hline
\end{tabular}

The IR-MAD scheme holds back one-third of time-invariant pixels to evalute the normalization procedure by calculating the means and variances of target images, before and after normalization, for performing statistical hypothesis tests for equality in means and variances of the time-invariant pixels in the reference and nomalized target images (Canty, 2010). These results are given in Table 4 as 345 and 656 test pixels for the $2^{\text {nd }}$ and $5^{\text {th }}$ March images vs. the $7^{\text {th }}$ March reference image, respectively; 112 test pixels for the $27^{\text {th }}$ April vs. the $20^{\text {th }}$ April reference image; and 262 and 173 test pixels for the $4^{\text {th }}$ and $16^{\text {th }}$ June images vs. the 23th May reference image, respectively. The significance value $(p<0.05)$ for the t-test for equal means and for the F-test for equal variances 
indicate that the hypothesis of equality cannot be rejected for any of the spectral bands in datasets, so we conclude that the normalization has been successful.

Table 3. Red and Near-Infrared wavebands behavior over early growing season associated with hybrid ATCOR/IR-MAD technique (normalized surface reflectance) across Wytham flux tower extent

\begin{tabular}{|c|c|c|c|c|c|c|c|c|}
\hline \multirow{2}{*}{$\begin{array}{l}\text { Acquisition } \\
\text { Date }\end{array}$} & \multicolumn{4}{|c|}{ Red Waveband from ATCOR/IR-MAD } & \multicolumn{4}{|c|}{ NIR Waveband from ATCOR/IR-MAD } \\
\hline & Mean & Median & SD & $\mathrm{CV}$ & Mean & Median & SD & $\mathrm{CV}$ \\
\hline $2^{\text {nd }}$ March & 5.95 & 5.90 & 1.31 & 22.00 & 27.47 & 27.12 & 3.05 & 11.10 \\
\hline $5^{\text {th }}$ March & 6.17 & 6.00 & 1.15 & 18.63 & 27.64 & 27.48 & 3.01 & 10.90 \\
\hline $7^{\text {th }}$ March & \multicolumn{4}{|c|}{ Reference Image } & \multicolumn{4}{|c|}{ Reference Image } \\
\hline $20^{\text {th }}$ April & \multicolumn{4}{|c|}{ Reference Image } & \multicolumn{4}{|c|}{ Reference Image } \\
\hline $27^{\text {th }}$ April & 6.07 & 6.00 & 0.97 & 15.98 & 46.86 & 45.88 & 5.85 & 12.50 \\
\hline $23^{\text {rd }}$ May & \multicolumn{4}{|c|}{ Reference Image } & \multicolumn{4}{|c|}{ Reference Image } \\
\hline $4^{\text {th }}$ June & 3.38 & 3.32 & 0.52 & 15.38 & 81.40 & 81.53 & 7.21 & 8.86 \\
\hline $16^{\text {th }}$ June & 3.62 & 3.41 & 0.68 & 18.78 & 74.72 & 7592 & 7.21 & 9.65 \\
\hline
\end{tabular}

Table 4. Paired $t$-tests and F-tesets for equal means and variances between target images and normalized images using IR-MAD normalization method

\begin{tabular}{|c|c|c|c|c|c|c|c|c|c|c|c|c|}
\hline \multirow{3}{*}{$\begin{array}{c}\text { Acquisition } \\
\text { Date }\end{array}$} & \multicolumn{6}{|c|}{ Mean } & \multicolumn{6}{|c|}{ Variance } \\
\hline & \multicolumn{3}{|c|}{ t-Statistic } & \multicolumn{3}{|c|}{ P-value } & \multicolumn{3}{|c|}{ F-Statistic } & \multicolumn{3}{|c|}{ P-value } \\
\hline & B1 & B2 & B3 & B1 & $\mathrm{B} 2$ & B3 & B1 & B2 & B3 & B1 & $\mathrm{B} 2$ & B3 \\
\hline $2^{\text {nd }}$ March & 0.176 & 0.200 & 0.126 & 0.860 & 0.842 & 0.899 & 1.008 & 1.006 & 1.007 & 0.939 & 0.958 & 0.952 \\
\hline $5^{\text {th }}$ March & -0.09 & $-\mathrm{NaN}$ & 0.580 & 0.927 & $\mathrm{NaN}$ & 0.562 & 1.002 & 1.000 & 1.000 & 0.980 & 1.000 & 0.998 \\
\hline $27^{\text {th }}$ April & -0.39 & -0.73 & -0.22 & 0.692 & 0.466 & 0.827 & 1.006 & 1.012 & 1.002 & 0.973 & 0.952 & 0.990 \\
\hline $4^{\text {th }}$ June & 0.322 & 0.287 & -0.10 & 0.748 & 0.775 & 0.919 & 1.006 & 1.005 & 1.002 & 0.960 & 0.971 & 0.991 \\
\hline $16^{\text {th }}$ June & -0.19 & -0.25 & 0.099 & 0.844 & 0.802 & 0.922 & 1.049 & 1.026 & 1.000 & 0.754 & 0.868 & 0.996 \\
\hline
\end{tabular}

\section{Early in Season Normalization, Leaf-off Conditions}

Three images were available from $2^{\text {nd }}$ March (UK-DMC2), $5^{\text {th }}$ March (UK-DMC2), and $7^{\text {th }}$ March (DEIMOS), acquired using the same sensor (SLIM-6-22) and spatial resolution ( 22 metres at nadir). The image from $7^{\text {th }}$ March was selected as the reference image for the leaf-off period, based on visual assessment of quality and the fact that it was acquired close to nadir for the study area. The other March images were normalized to the $7^{\text {th }}$ March data as a reference image.

\section{Early Spring Normalization, Middle Leaf-on Conditions}

The reference image to perform relative illumination and normalization of leaf-on conditions during mid-spring was considered based on near-nadir situation for the study area. The $27^{\text {th }}$ April was normalized to the $20^{\text {th }}$ April absolute corrected reflectance as a reference image.

\section{Early Summer Normalization, Leaf-on Conditions}

The reference image to perform relative illumination and nadir normalization of leafon conditions during early summer was considered based on their high solar elevation and cloud free conditions. Therefore, the $4^{\text {th }}$ and $16^{\text {th }}$ June images were normalized to the $23^{\text {rd }}$ May absolute corrected reflectance as a reference image. 


\section{Defining the Flux Footprint Coverage}

A buffer distance of $400 \mathrm{~m}$ centred on the flux tower location was considered as a the long-term pattern of daytime flux footprint, referred to here as the circular flux footprint $(\mathrm{CFF})$, which corresponds to an array of $37 \times 36$ DMC pixels (with $22 \mathrm{~m}$ pixel size) and $3 \times 3$ MODIS pixels (with $250 \mathrm{~m}$ pixel size) centred on the tower.

The area-weighted flux footprint was estimated using site properties. Canopy height was determined using an airborne Light Detection and Ranging (LiDAR) survey of the site in 2009. Meteorological data from the nearest MetOffice weather station (Lat: 51 ${ }^{\circ} 46^{\prime} \mathrm{N}$; Lon: $1^{\circ} 46^{\prime} \mathrm{W}$; Alt: $63.4 \mathrm{~m}$ ) revealed two prevailing wind directions during 2010: $225^{\circ}$ (south-west) and $315^{\circ}$ (north-west). Therefore, the flux footprint weighted was also modelled with wind from each of these directions, under both moderate and unstable conditions, i.e. $-0.1<Z_{m} / L<-0.001$ at flux tower site with $Z_{m} / Z_{0}$ of 19.23 , i.e. $Z_{m}=25 \mathrm{~m}$ and $Z_{0}=1.30 \mathrm{~m}$. The weighted flux footprint was hereafter termed as the realistic flux footprint (RFF). Figure 6 illustrates the estimated horizontal position of $90 \%$ cumulative footprints for two prevailing wind directions under different atmospheric stability conditions. The spatial coverage of red and yellow points indicates the RFF under unstable and moderately stable conditions respectively.

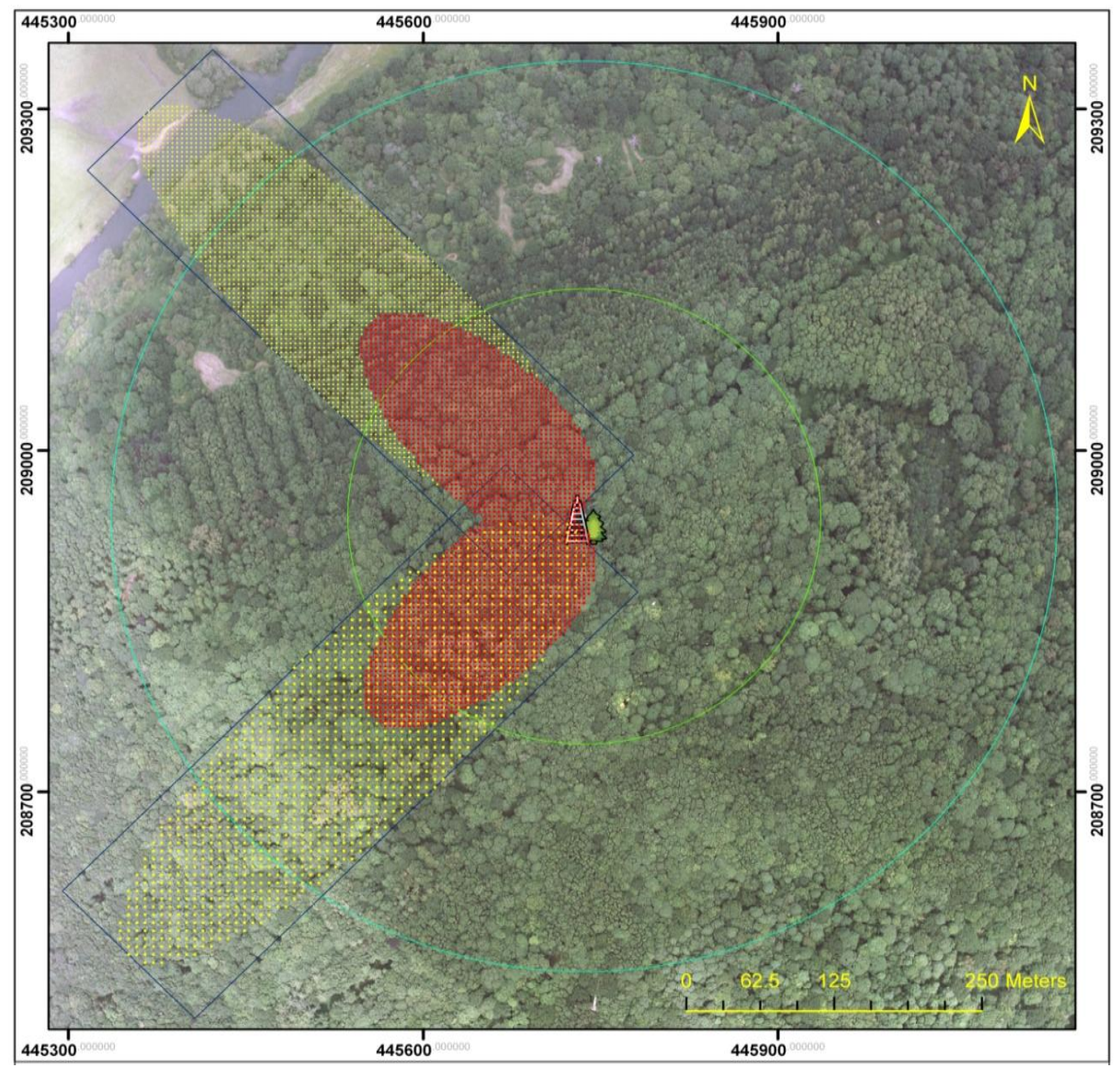

Figure 6. Flux footprint weighted, overlaid on an aerial image of Wytham Woods, based on two prevailing upwind directions (i.e. $225^{\circ}$ and $315^{\circ}$ ) on the crosswind integrated surface coverage under moderate (i.e. yellow points) and unstable (i.e. red points) atmospheric stability conditions. Green and Cyan lines show the buffer distance off by $200 \mathrm{~m}$ and $400 \mathrm{~m}$ around flux tower site, respectively. 


\section{Statistical Analysis}

Non-parametric statistical test was conducted to determine whether the flux footprint variability in terms of micrometeorological conditions would cause a significant difference in the NDVI over a growing season. Mood's Median test (a robust test with respect to other non-parametric test) was conducted to test the null hypothesis for equality in NDVI for investigating the uncertainty in terms of imprecise definition of flux footprint. In this respect, the null hypotheses are as follows.

$\mathrm{H}_{0}$ : Under long-term pattern of daytime flux footprint, circular flux footprint coverage, there is no significant difference in median NDVI over short time intervals in leaf-off condition.

$\mathrm{H}_{0 \text { : }}$ Under different atmospheric stability conditions there is no significant difference in median NDVI between realistic and long-term circular flux footprints depending on prevailing wind directions.

Moreover, the non-parametric Wilcoxon rank-sum test (Wilcoxon, 1945) was conducted for comparison of differences between two independent NDVI from DMC and MODIS over short time intervals in the leaf-off period.

\section{Results and Discussion}

\section{Temporal Variability of DMC NDVI across Circular Flux Footprint}

The descriptive statistics and histogram distribution of the DMC NDVI from within the circular flux footprint (CFF) across Wytham flux tower extent are presented by Table 5 and Figure 7, respectively, which indicate its variability through the growing season as expected. The mean value of NDVI was relatively high across the CFF coverage during the early Spring in March-April, perhaps a result of flourishing understory canopy and many sparse evergreen coniferous trees. This was followed by a rise during April-May as the forest canopy came into leaf. High values of NDVI in midJune could have resulted from late developing trees such as oak reaching full photosynthesis capacity.

Table 5. Descriptive Statistics on DMC NDVI across Wytham flux tower (circular flux footprint) site over a growing season in 2010

\begin{tabular}{clllll}
\hline Acquisition Date & Mean & Median & Std. Deviation & Skewness & CV \% \\
\hline $2^{\text {nd }}$ March & 0.6468 & 0.6375 & 0.0492 & 1.059 & 7.61 \\
$5^{\text {th }}$ March & 0.6363 & 0.6285 & 0.0442 & 1.610 & 6.95 \\
$7^{\text {th }}$ March & 0.6292 & 0.6232 & 0.0440 & 1.542 & 6.99 \\
$20^{\text {th }}$ April & 0.7280 & 0.7241 & 0.0354 & 0.194 & 4.86 \\
$27^{\text {th }}$ April & 0.7905 & 0.7905 & 0.0402 & -0.139 & 5.09 \\
$23^{\text {rd }}$ May & 0.9012 & 0.9054 & 0.0184 & -2.925 & 2.04 \\
$4^{\text {th }}$ June & 0.9191 & 0.9207 & 0.0111 & -1.474 & 1.21 \\
$16^{\text {th }}$ June & 0.9080 & 0.9112 & 0.0160 & -2.114 & 1.76 \\
\hline
\end{tabular}

As Figure 7 shows, the distribution of NDVI values during leaf-off conditions early in the season $\left(2^{\text {nd }}-7^{\text {th }}\right.$ March) was positively skewed, probably due to the mixture of understory and sparse coniferous trees present (Street et al., 2007), while is negatively 
skewed during leaf-on conditions (May - June) when the canopy response is dominated by the intact tree canopy. In general, the distribution of NDVI was positively skewed and centred on 0.6 in leaf-off conditions and negatively skewed and centred on 0.9 in leaf-on conditions. This suggests that the spatial variability of the canopy changed significantly during transition from leaf-off to leaf-on conditions because of canopy patchiness at high spatial resolution, i.e. scales finer than a MODIS pixel, for example, at $22 \mathrm{~m}$ spatial resolution. This means that using directly MODIS vegetation indices as a proxy of $\mathrm{CO}_{2}$ flux incorporates uncertainty in the scaling process from the EC flux tower to landscape and regional level without precise definition of area contributing to $\mathrm{CO}_{2}$ flux measurements in Wytham Woods.

2nd March 2010

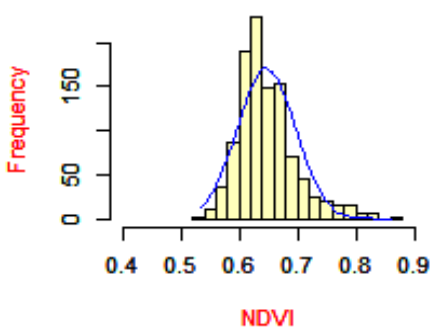

20th April 2010

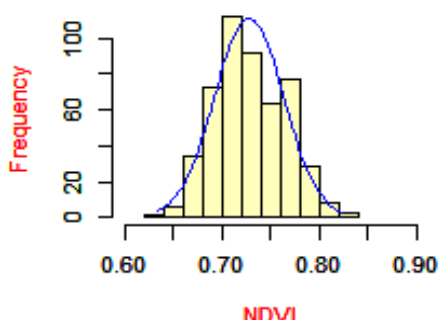

23rd May 2010

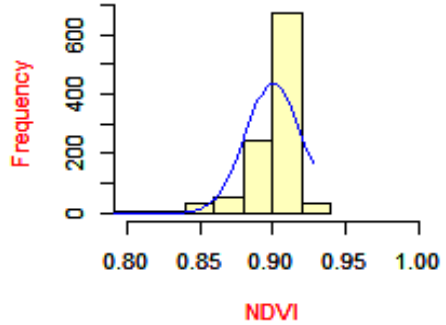

5th March 2010

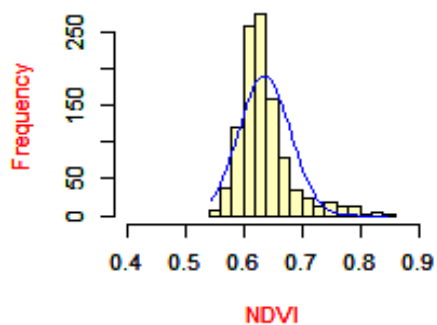

27th April 2010

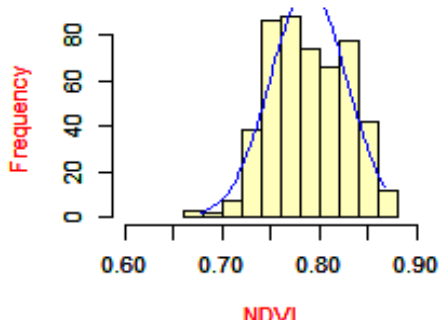

4th June 2010

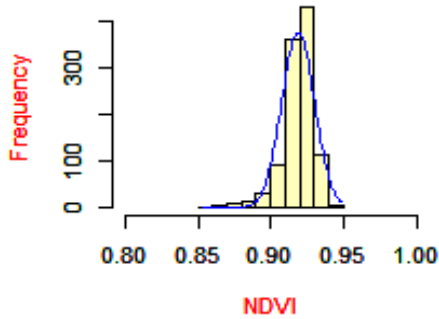

7th March 2010

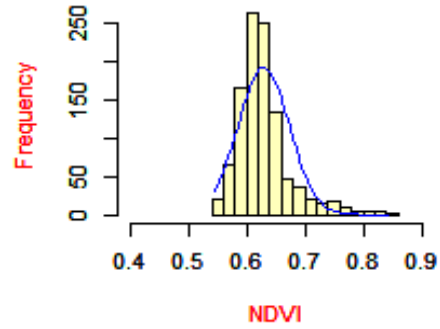

Figure 7. Histogram distribution of the DMC NDVI based on the ATCOR/IR-MAD correction

Figure 8 presents the behaviour of canopy reflectance for Red and Near-Infrared spectral bands associated with the hybrid ATCOR/IR-MAD technique from within the CFF during the 2010 growing season, and Table 5 shows its central tendency and dispersion indices. Typically, canopy reflectance varies approximately between 0 and 10 in the Red waveband, and 20 and 100 in the Near-Infrared waveband. In the main, temperate broadleaf and mixed forests have strong absorption in Red waveband due to chlorophyll content, and strong reflectance in the Near-Infrared waveband. There was 
also an unexpected decrease in the NIR band and increase slightly in the Red band on $16^{\text {th }}$ June, possibly due to the influence of adjacent cloud shadow as depicted by Figure 8.
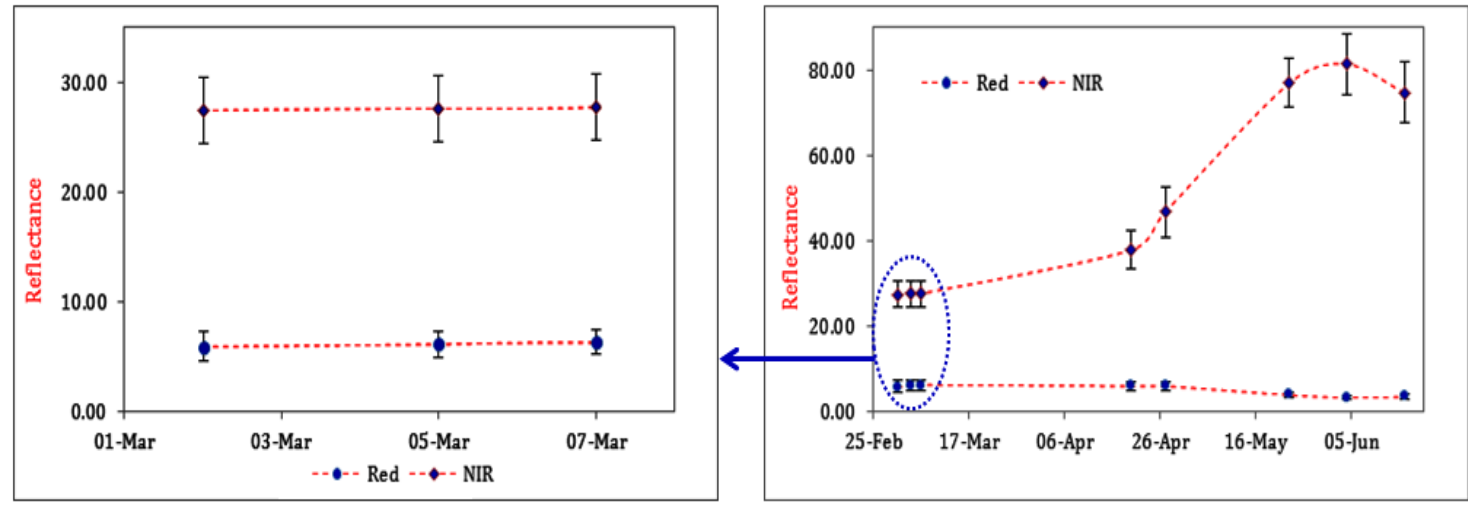

Figure 8. DMC Red and Near-Infrared waveband behaviour associated with the hybrid ATCOR/IR-MAD technique across Wytham flux tower extent, i.e. circular flux footprint (CFF), over a growing season in 2010

The availability of three acquisitions within five days during early March, when we would expect little change in the biophysical properties of Wytham Woods, provides the opportunity to look at the sensitivity of NDVI to extraneous factors such as changes in viewing conditions, atmospheric variability and sampling error. Table 6 and Figure 8 show that the reflectance and the NDVI determined from DMC data changed very little during this period (less than 0.018 and 0.015 mean and median NDVI, selectively). This result is important in the context of MODIS, as the MOD13Q1 product is derived from sampling observations within a 16-day window. It is therefore not suitable for identifying the precise moment of change or for following rapidly fluctuating NDVI values. Two MODIS images related to the period $2^{\text {nd }}-7^{\text {th }}$ March, the first derived from the 16-day window $18^{\text {th }}$ February $-5^{\text {th }}$ March, and the second from $6^{\text {th }}-21^{\text {st }}$ March. Median NDVI from the circular flux footprint was slightly higher in the later MODIS image, but the difference was not statistically significant (Wilcoxon-Rank-Sum test, $\mathrm{W}=21$, $\mathrm{p}$ - value $=0.09$ ).

Table 6. Difference below and above overall Median of the NDVI values across the longterm circular flux footprint in Wytham Woods over a-five day interval of leaf-off condition in March 2010

\begin{tabular}{ccccc}
\hline Difference from & \multicolumn{2}{c}{ DMC NDVI over a-five day interval in early March 2010 } & \multirow{2}{*}{ Total } \\
\cline { 2 - 4 } Median & $2^{\text {nd }}$ March & $5^{\text {th }}$ March & $7^{\text {th }}$ March & \\
\hline$\leq$ Median & 46 & 51 & 56 & 153 \\
$>$ Median & 54 & 49 & 44 & 147 \\
Total & 100 & 100 & 100 & 300 \\
\hline
\end{tabular}

Figure 9 illustrates central tendency and normality plots of samples derived for these short-terms intervals. For each Q-Q plot, the tendency is not linear. Thus, it is reasonable to assume those samples are from a non-normal population. Furthermore, the 
slopes in the Q-Q plots from $5^{\text {th }}$ and $7^{\text {th }}$ March are similar, so it is appear that the variances are the same, but vary with $2^{\text {nd }}$ March.
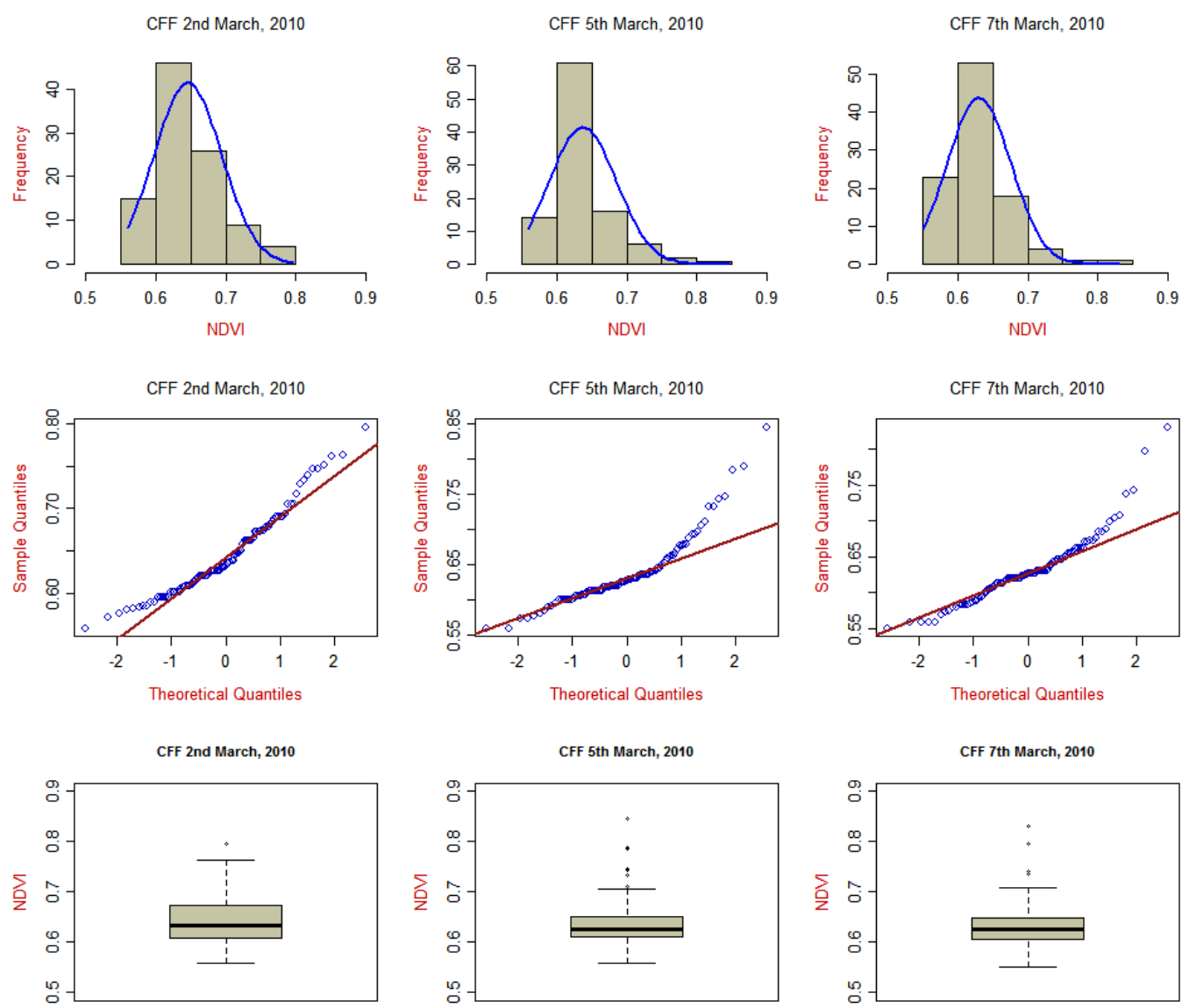

Figure 9. Central tendency and normality plots of samples derived for short-terms intervals DMC imagery in early March 2010

The Mood's median test using the Pearson's Chi-square test (Zar, 2010) was conducted to compare the medians of sample data sets (testing first null hypothesis). Table 6 presents the results of the Mood's Median test between three data sets of DMC NDVI during early in season. The overall median is equal to 0.6271 and the Pearson Chi-square statistics is equal to $2.001(\mathrm{~N}=300 ; \mathrm{df}=2$; and $\mathrm{p}$-value $=0.368)$, which means there is no significant difference in the NDVI data sets through this short time interval. The percentage of the absolute deviation from the overall median was calculated for these three samples are approximately $3.4 \%\left(2^{\text {nd }}\right.$ March: $3.8 \% ; 5^{\text {th }}$ March 3.2\%; and $7^{\text {th }}$ March: 3.1 March), which is less than the 5\% error in DMC NDVI across southern England predicted by Wilson et al. (2012) due to aerosol patchiness (i.e. unresolved variation in space and time).

Figure 10 compares the NDVI values from an array of $3 \times 3$ MODIS pixels centred on the flux tower location (i.e. approx. $400 \mathrm{~m}$ buffer), with the averaged values of an array of $37 \times 36$ DMC pixels within the same area. The error bars on the Y-axis (Figure 10a) show \pm 1 standard deviation of the DMC NDVI and MOD13Q1 values. The two data sets were highly correlated $\left(\mathrm{R}^{2}=0.974, \mathrm{p}<0.05\right)$, showing that data from the DMC SLIM-6-22 sensor closely matched MODIS over this period of time (Figure 10b). 
However, the DMC NDVI values are higher than MODIS NDVI at all dates through growing season, which indicates a significant bias. The source of this bias is unknown; however, it is most likely due to differences in sun-sensor geometry between DMC and MODIS. In addition, there was a small unavoidable spatial mismatch between MODISand DMC-based subsets across the CFF due to the different pixel sizes. A further factor to consider is the difference in the wavelength of maximum sensitivity for Red and Near-Infrared bands, which are $660 \mathrm{~nm}$ and $835 \mathrm{n}$ for DMC, and $645 \mathrm{~nm}$ and $858 \mathrm{~nm}$ for MODIS, respectively.
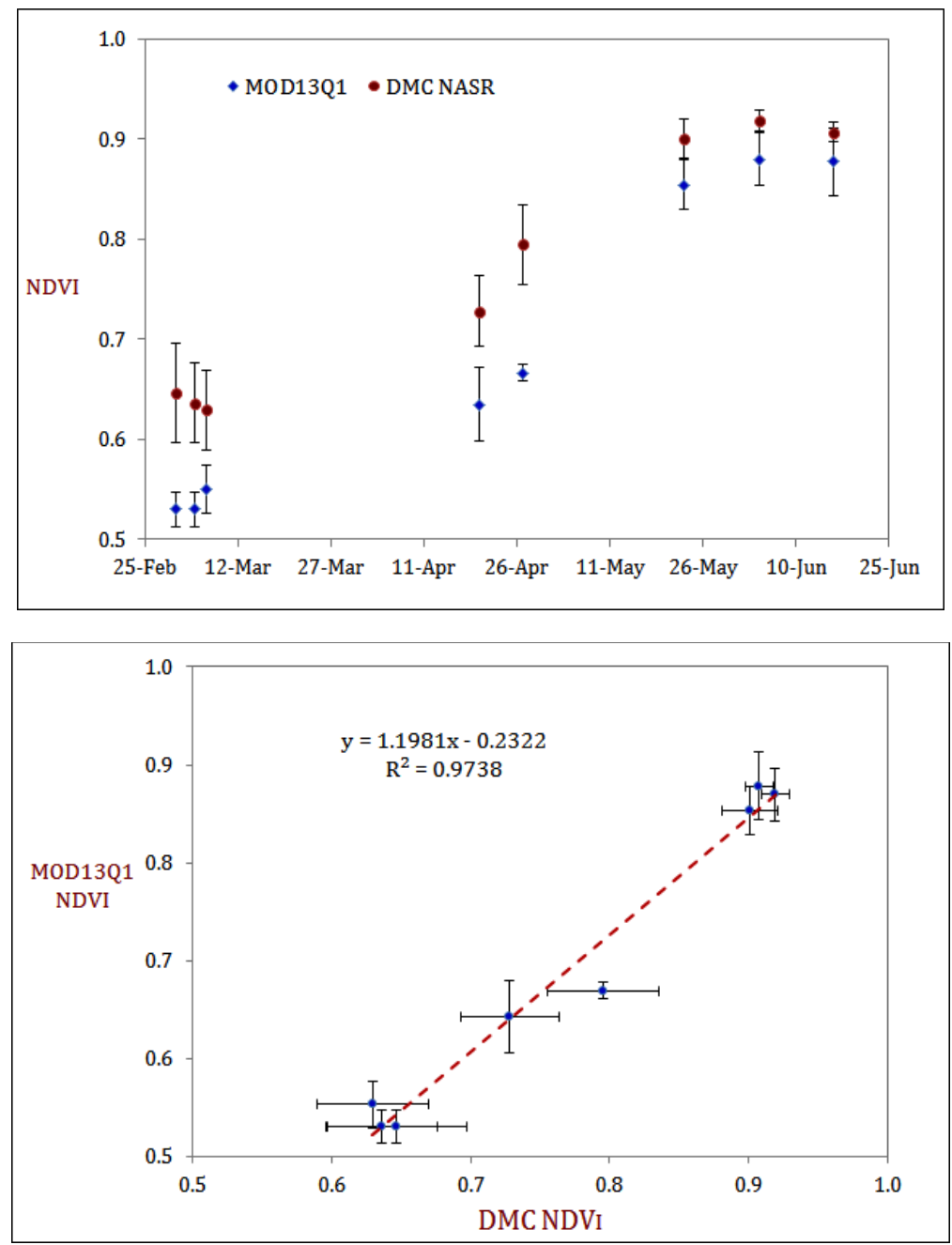

Figure 10. Comparison of NDVI derived from DMC constellation and MOD13Q1: NDVI across Wytham's circular flux footprint over early growing season in 2010

\section{Temporal Variability of DMC NDVI across Realistic Flux Footprint}

Since the observed data from within the CFF and RFFs were not normally distributed, median absolute deviation (MAD), a robust measure of statistical dispersion that is more resilient to outliers in a data set than the standard deviation (Huber, 2004), was computed to use as a consistent estimate of the standard deviation, i.e. $\hat{\sigma}=b \times M A D$ where $b$ is a constant scale factor, and equal to the inverse of third 
quintile of underlying distribution $\left(Q_{3}\right)$. The MAD is defined as the median of the absolute deviations from the median of data set, i.e. $\operatorname{MAD}=\operatorname{Med}\left(\left|x_{i}-\operatorname{Med}\left(x_{i}\right)\right|\right.$ where $x_{i}$ refers to NDVI. The main results presented in Figure 11 compare the temporal trend of DMC NDVI from within the CFF with the trend of DMC NDVI from four realistic flux footprints, NW Moderate, NW Unstable, SW Moderate, and SW unstable conditions.

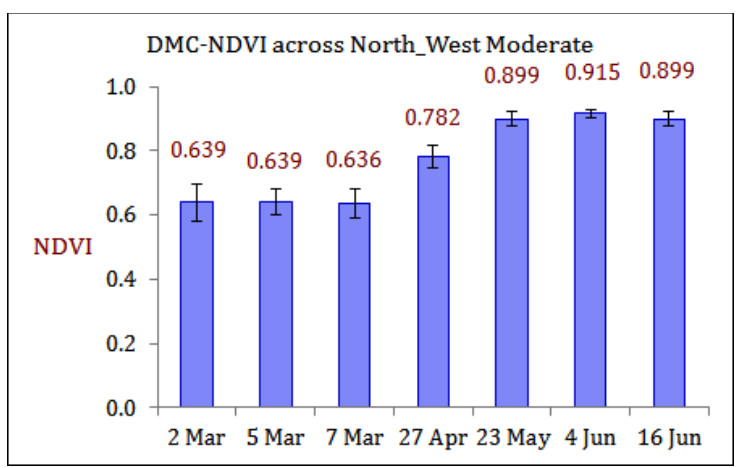

(a)

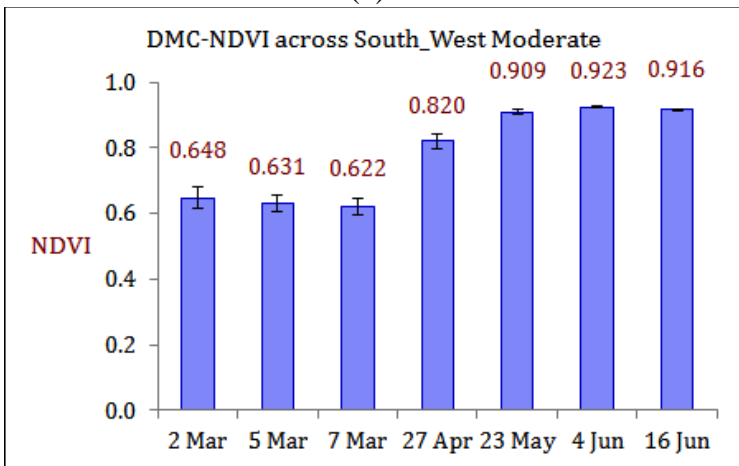

(c)

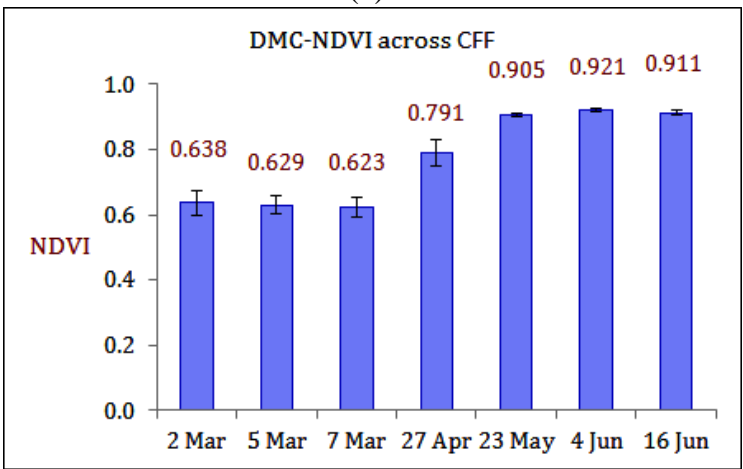

(e)

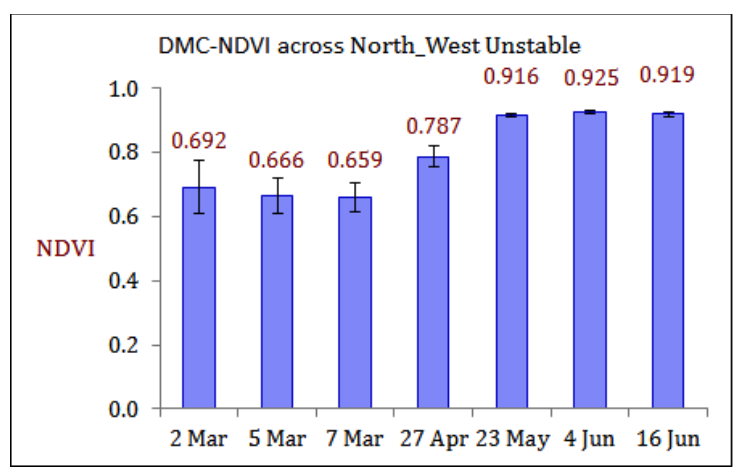

(b)

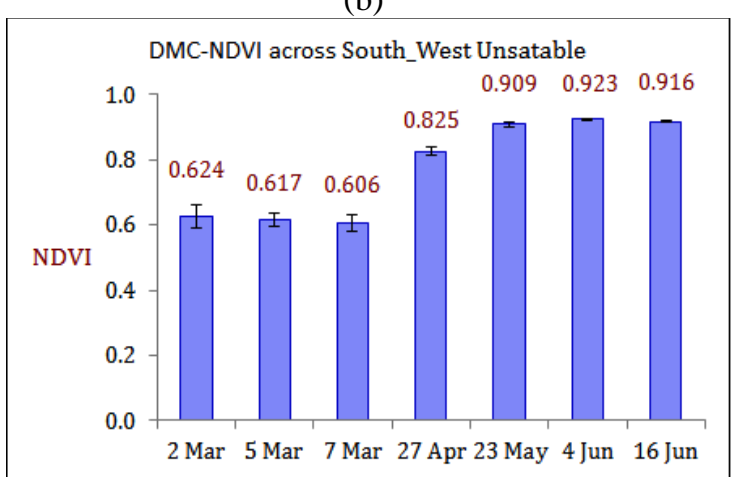

(d)

Figure 11. Plot of ATCOR/IR-MAD based median of DMC NDVI and MODIS NDVI across various flux footprint coverage over growing season in 2010 as: (a) RFF NW Moderate, (b) RFF NW Unstable, (c) RFF SW Moderate, (d) RFF SW Unstable, and (e) DMC NDVI over $C F F$; Error bars show the estimated standard deviation based on the median absolute deviation (Huber, 2004).

As expected, the variability in the DMC NDVI across all flux footprint coverage decreased during developing canopy greenness, which shows that the forest canopy was 
more homogenous in leaf-on than leaf-off condition, an obvious trend in temperate deciduous forests. Of particular interest in the NW Moderate RFF is relatively high variability in temporal DMC NDVI trend, caused by the footprint fetch reaching beyond the forest canopy and including some of the surrounding landscape. These extraneous patches contributed to the composite surface reflectance, and therefore the VI.

The median difference between the CFF and all RFFs was computed to show the spatial variability of the DMC NDVI throughout the growing season. As Figure 12 illustrates, there were three distinct phases.

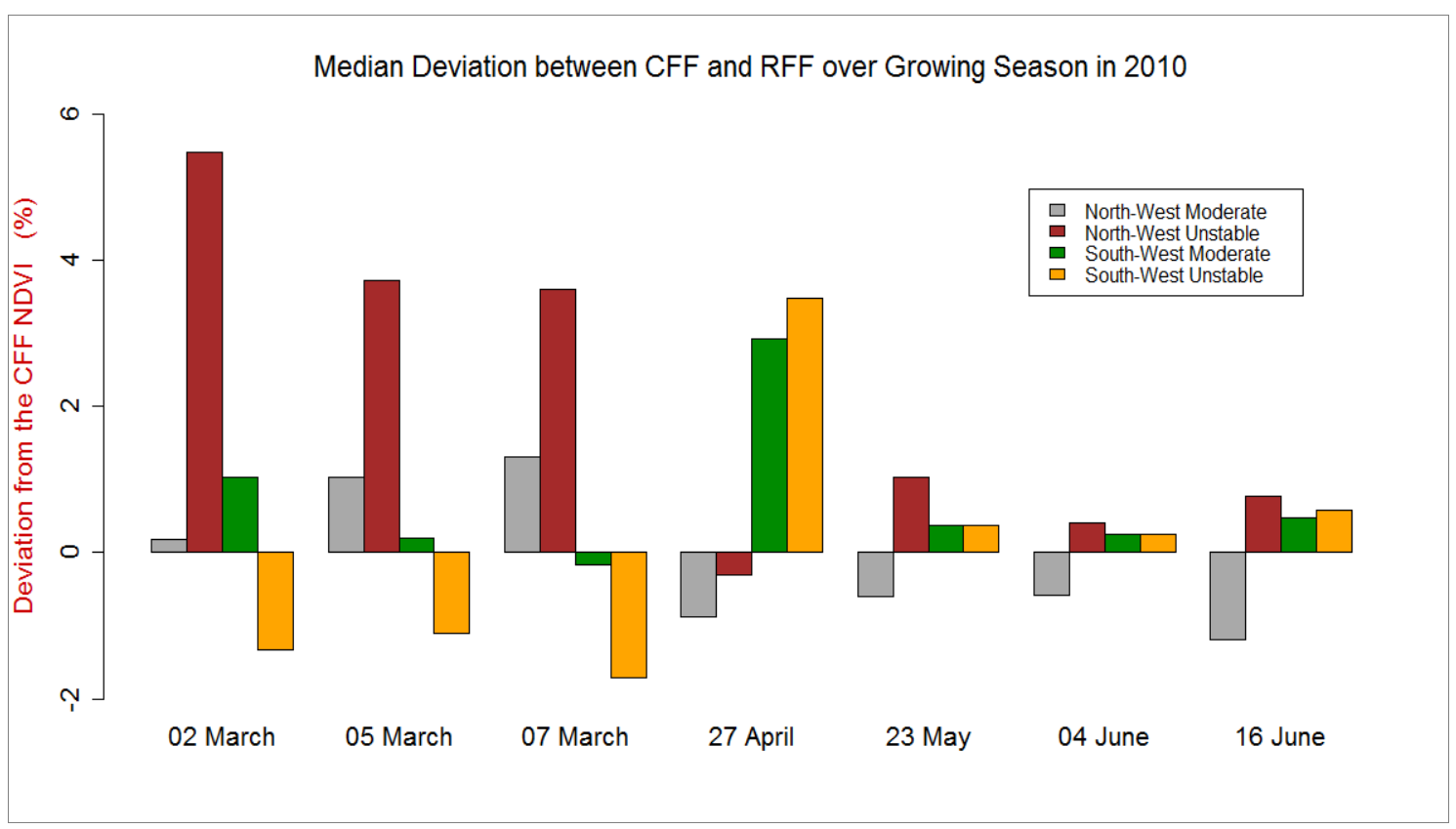

Figure 12. The Median DMC NDVI as percentage deviation from the CFF NDVI for each of the weighted flux footprint coverage

The first phase, covering five days in March showed that median NDVI computed from the RFF differed from that computed from the CFF by up to $5 \%$ depending upon the strength and direction of the wind. The NDVI of the RFF was larger than that from the CFF on most occasions, but the percentage difference varied. The sole exception was a strong wind from the south-west, which caused the NDVI of the RFF to be less than that from the CFF. The second phase, represented by the data from $27^{\text {th }}$ April showed smaller differences between the NDVI of the RFF and the CFF. A south-westerly wind at this time of the year caused the NDVI from the RFF to be up to $4 \%$ higher than the $\mathrm{CFF}$, whereas a north-westerly wind caused a slight reduction in the NDVI from RFF compared to the CFF (around 1\%). The third phase comprised data collected in May and June, when the tree canopy was fully developed. The NDVI values from the RFF differed slightly from the CFF (around 1-2\%) during this period, and the direction of the difference was the same on each occasion: a moderate wind from the north-west resulted in the NDVI from the RFF being slightly lower than the CFF, whereas the other conditions all lead to a slight increase in RFF compared with CFF. The relatively high percentage of the median deviation from unstable RFF with respect to moderate RFF, in particular early in the season, shows the small area of contributing flux measurements 
are more homogenous than the larger area, because as fetch distance increases, the similarity of biophysical properties are more similar to the CFF.

Then the Mood's Median test was conducted to test the effects of flux footprint variability in the NDVI concerning wind direction and atmospheric stability condition. Table 7 shows the results of this investigation under two atmospheric stability conditions: moderate and unstable conditions, respectively, whether the median DMC NDVI differs between the CFF and those derived from weighted flux footprint (i.e. $\mathrm{RFF}_{\mathrm{S}}$ ) , during the study period. The assumption was that there were no median difference between the CFF and the weighted RFF. While, there are complex results for all contexts, the north-west unstable RFF shows that there is significant difference ( $p$ value $<0.05)$ through the period of growing season. In the main, the CFF which covers various canopy patches such as secondary, plantation, and ancient canopies varies. This suggests that there is significant spatial variability across the CFF coverage. Since both wind direction and atmospheric stability condition can influence the footprint fetch (i.e. shape and size), the weighted RFF coverage is relatively more homogeneous than the CFF. Therefore, using MODIS NDVI as a proxy for GPP in Wytham woods (pixel size from $250 \mathrm{~m}$ to $1 \mathrm{~km}$ ) is problematic, because validating MODIS NDVI derived GPP using the tower specific $\mathrm{CO}_{2}$ flux measurements needs to take into account local spatial variability.

Table 7. Mood's test between the CFF and RFF in terms of wind direction and atmospheric stability condition across Wytham flux tower extent over growing season in 2010, degrees of freedom for each case is equal to one.

\begin{tabular}{|c|c|c|c|c|c|c|c|}
\hline \multicolumn{8}{|c|}{ NW Moderate RFF vs. CFF } \\
\hline & $2^{\text {nd }}$ March & $5^{\text {th }}$ March & $7^{\text {th }}$ March & $27^{\text {th }}$ April & $23^{\text {rd }}$ May & $4^{\text {th }}$ June & $16^{\text {th }}$ June \\
\hline $\mathrm{N}$ & 150 & 150 & 150 & 150 & 150 & 150 & 150 \\
\hline Median & 0.6348 & 0.6305 & 0.6271 & 0.7924 & 0.9006 & 0.9179 & 0.9085 \\
\hline Chi-square & 0.120 & 6.454 & 3.414 & 1.920 & 9.015 & 9.720 & 8.339 \\
\hline P Value & 0.729 & 0.011 & 0.065 & 0.166 & 0.003 & 0.002 & 0.004 \\
\hline \multicolumn{8}{|c|}{ NW Unstable RFF vs. CFF } \\
\hline $\mathrm{N}$ & 130 & 130 & 130 & 130 & 130 & 130 & 130 \\
\hline Median & 0.6452 & 0.6336 & 0.6308 & 0.7847 & 0.9048 & 0.9217 & 0.9141 \\
\hline Chi-square & 8.493 & 17.333 & 15.397 & 11.093 & 10.922 & 8.493 & 8.493 \\
\hline P Value & 0.004 & 0.000 & 0.000 & 0.001 & 0.001 & 0.004 & 0.004 \\
\hline \multicolumn{8}{|c|}{ SW Moderate RFF vs. CFF } \\
\hline $\mathrm{N}$ & 150 & 150 & 150 & 150 & 150 & 150 & 150 \\
\hline Median & 0.6455 & 0.6285 & 0.6271 & 0.7934 & 0.9048 & 0.9212 & 0.9132 \\
\hline Chi-square & 6.454 & 1.334 & 0.857 & 3.000 & 5.918 & 2.260 & 1.614 \\
\hline P Value & 0.011 & 0.248 & 0.355 & 0.083 & 0.015 & 0.133 & 0.204 \\
\hline \multicolumn{8}{|c|}{ SW Unstable RFF vs. CFF } \\
\hline $\mathrm{N}$ & 130 & 130 & 130 & 130 & 130 & 130 & 130 \\
\hline Median & 0.6321 & 0.6246 & 0.6217 & 0.7924 & 0.9048 & 0.9212 & 0.9138 \\
\hline Chi-square & 0.103 & 2.172 & 4.333 & 2.773 & 15.532 & 5.175 & 6.240 \\
\hline P Value & 0.749 & 0.141 & 0.037 & 0.096 & 0.000 & 0.023 & 0.012 \\
\hline
\end{tabular}

However, before we can conclude that the observed differences in NDVI were real, and a function of the canopy area sensed, we must set the measured variation in NDVI 
into context. In particular, Wilson et al. (2012) modelled the spatial variability of aerosol amount over southern England and showed that NDVI could have a relative variation of up to $5 \%$ from that source alone. Thus, the observed differences in NDVI between the RFF and the CFF are comparable in magnitude to the uncertainty in the atmospheric correction, and could even be due to real variations in aerosol amount and type, caused by different air masses over the site, rather than actual variations in the area of the canopy sensed.

\section{Conclusion}

The available evidence shows that NDVI is a reliable estimator of biophysical variables closely related to photosynthesis capacity (i.e. as a proxy of $\mathrm{CO}_{2}$ flux) at various spatial and temporal scales over a wide range of plant functional types (Sellers et al., 1992, Tucker, 1979). The research reported in this paper has shown that this spectral index can be accurately measured using data from the DMC constellation, and that this system has a number of important advantages over the more commonly used systems such as MODIS. First, the data from DMC are of finer spatial resolution, which means that smaller areas of uniform land cover can be sensed, and also that heterogeneous sites can be studied. This is particularly important if the aim is to compare the satellite observation with ground measurements, either for model calibration or for product validation purposes. In the specific example studied, the uncertainty in NDVI as a result of differences in the conditions of measurement did affect the median NDVI, however, the difference was less than that due to uncertainty in the atmospheric correction. Thus, in the case of Wytham Woods, it is more important to improve the representation of aerosols in the atmospheric model used than replace the generalised circular flux footprint with a realistic flux footprint. However, that does not mean that computing and investigating the RFF is not important, because an accurate estimate of the RFF is crucial in linking plant spectral properties, notably NDVI, to the EC data measured from the flux tower.

The second advantage of DMC over MODIS concerns the temporal precision of the measurements. The 16-day sampling window of MODIS could become a limitation at certain times during the growing season. In the case of Wytham Woods in 2010, the DMC time series shows an increase in NDVI between $20^{\text {th }}$ and $27^{\text {th }}$ April, whereas the MODIS data show no significant change between these dates.

DMC is not without its limitations for this task, and perhaps the greatest is the large off-nadir view angle of some pixels as a consequence of the very wide swath. The eight DMC images of Wytham Woods acquired in 2010 were imaged at view zenith angles from 0.82 to 28.74 .

In summary, the objectives set out at the start of the chapter have been achieved. A time series of ten DMC images were acquired and inter-calibrated, and these provided a unique insight into the seasonal changes occurring in one of the most important ecological sites in the UK. The author is not aware of any other analysed time series of multispectral data of comparable spatial resolution and temporal frequency from southern England. The accuracy of the calibrated DMC data was assessed by comparing it with MODIS, and although there was evidence of a consistent bias, there was a strong linear relationship between the two sensors. The heterogeneity of Wytham Woods had greatest impact on the DMC data early in the season, and this highlighted the importance of understanding how the flux footprint varies with weather conditions. As 
the canopy began to green-up, the precision of temporal sampling became more important. The rapid rise in NDVI in late Spring was captured effectively by DMC images one week apart, whereas the MODIS data from the same period was less clear.

The research showed that differences in median NDVI between the CFF and the RFF decreased consistently as the season progressed, so the advantages of DMC over MODIS are likely to be most important when the canopy is greening-up in late-Spring, when NDVI is changing rapidly and the when the woodland canopy is still quite open.

\section{REFERENCES}

[1] Baldocchi, D. (2008): Turner Review No. 15. Breathing of the terrestrial biosphere: lessons learned from a global network of carbon dioxide flux measurement systems Australian Journal of Botany 56:1 - 26.

[2] Baldocchi, D., Falge, E., Gu, L., Olson, R., Hollinger, D., Running, S., Anthoni, P., Bernhofer, C., Davis, K.J., Evans, R., Fuentes, J., Goldstein, A., Katul, G., Law, B., Lee, Z., Malhi, Y., Meyers, T., Munger, W.J., Oechel, W., Paw, U.K.T., Pilegaard, K., Schmid, H.P., Valentini, R., Verma, S., Vesala, T., Wilson, K.B., Wofsy, S. (2001): FLUXNET: A New Tool to Study the Temporal and Spatial Variability of EcosystemScale Carbon Dioxide, Water Vapor, and Energy Flux Densities - Bulletin of the American Meteorological Society 82: 2415 - 2434.

[3] Burba, G., Anderson, D. (2010): A Brief Practical Guide to Eddy Covariance Flux Measurements, USA, LI-COR Biosciences.

[4] Canty, M.J. (2010): Image Analysis, Classification, and Change Detection in Remote Sensing: With Algorithm for ENVI/IDL, Boca Raton, CRC Press Taylor \& Francis Group.

[5] Canty, M.J., Nielsen, A.A. (2008): Automatic radiometric normalization of multitemporal satellite imagery with the iteratively re-weighted MAD transformation - Remote Sensing of Environment 112:1025 - 1036.

[6] Chen, B., Black, T., Coops, N., Hilker, T., Trofymow, J., Morgenstern, K. (2009): Assessing Tower Flux Footprint Climatology and Scaling Between Remotely Sensed and Eddy Covariance Measurements - Boundary-Layer Meteorology 130: 137-167.

[7] Chen, B., Ge, Q., Fu, D., Liu, G., Yu, G., Sun, X., Wang, S., Wang, H. (2009): Upscaling of gross ecosystem production to the landscape scale using multi-temporal Landsat images, eddy covariance measurements and a footprint model - Biogeosciences Discussions 6: 11317 - 11345.

[8] Chen, B., Mlack, T.A., Coops, N.C., Hilker, T., Trofymow, J.A., Morgenstern, K. (2008): Assesing Tower Flux Footprint Climatology and Scaling Between Remotely Sensed and Eddy Covariance Measurements - Boundary-Layer Meteorology.

[9] Fluxnet. 2013. FLUXNET - Integrating Worldwide CO2, Water and Energy Flux Measurements [Online]. Available: http://fluxnet.ornl.gov/introduction [Accessed 19/10/2013.

[10] Forman, R.T. (1995): Land Mosaics: the ecology of landscape and regions - Cambridge, Cambrdge University Press.

[11] Forman, R.T., Godron, M. (1986): Landscape Ecology, New York, Wiley and Sons Ltd.

[12] Frohn, R.C. (1998): Remote Sensing for Landscape Ecology: New Metrcis Indicators for Monitoring, Modeling and Assessment of Ecosystems, Florida, CRC Press LLC.

[13] Gamon, J.A., Field, C.B., Bilger, W., Björkman, O., Fredeen, A.L. \& Peñuelas, J. (1990): Remote sensing of the xanthophyll cycle and chlorophyll fluorescence in sunflower leaves and canopies - Oecologia 85: 1-7.

[14] Gamon, J.A., Field, C.B., Goulden, M.L., Griffin, K.L., Hartley, A.E., Joel, G., Peñuelas, J., Valentini, R. (1995): Relationships Between NDVI, Canopy Structure, and 
Photosynthesis in Three Californian Vegetation Types - Ecological Applications 5:28 41.

[15] Glenn, E.P., Huete, A.R., Nagller, P.L., Nelson, S.G. (2008): Relationship Between Remotely-sened Vegetation Indices, Canopy Attributes and Plant Physiological Processes: What Vegetation Indices Can and Cannot Tell Us About the Landscape Sensors 8: 2136 - 2160.

[16] Hilker, T., Coops, N.C., Wulder, M.A., Black, T.A., Guy, R.D. (2008): The use of remote sensing in light use efficiency based models of gross primary production: A review of current status and future requirements - Science of The Total Environment 404: 411-423.

[17] Kim, J., Guo, Q., Baldocchi, D.D., Leclerc, M.Y., Xu., L., Schmind, H.P. (2006): Upscaling Fluxes from Tower to Landscape: Overlaying Flux Footprints on HighResolution (IKONOS) Images of Vegetation Cover - Agriculture and Forest Meteorology 136: 132 - 146.

[18] Lambers, H., Chapin Iii, F.S., Pons, T.L. (2008): Plant Physiological Ecology, New York, Springer.

[19] Masuoka, E., Roy, D., Wolfe, R., Morisette, J., Sinno, S., Teague, M., Saleous, N., Devadiga, S., Justice, C.O., Nickeson, J. (2011): MODIS Land Data Products: Generation, Quality Assurance and Validation. - In: Ramachandran, B., Justice, C.O., Abrams, M.J. (eds.) Land Remote Sensing and Global Environmental Change: NASA's Earth Observation System and the Science of ASTER and MODIS. New York, USA: Springer.

[20] Monteith, J.L. (1972): Solar Radiation and Productivity in Tropical Ecosystems - The Journal of Applied Ecology 9: 747-766.

[21] Nakaji, T., Ide, R., Oguma, H., Saigusa, N., Fujinuma, Y. (2007): Utility of Spectral Vegetation Index for Estimation of Gross CO2 Flux under Varied Sky Conditions Remote Sensing of Environment 109: 274-284.

[22] Prentice, C., Heimann, M., Sitch, S. (2000): The Carbon Balance of the Terrestrial Biosphere: Ecosystem Models and Atmospheric Observations - Ecological Applications 10: $1553-1573$.

[23] Richter, R. (2011): Atmospheric / Topographic Correction for Satellite Imagery. ATCOR-2/3 User Guide. Germany: DLR - German Aerospace Center.

[24] Rodwell, J.S. (ed.) (1991): Woodlands and Scrub - Cambridge: Cambridge University Press.

[25] Running, S.W., Nemani, R., Glassy, J.M., Thornton, P.E. (2000): MODIS Vegetation Production and Net Primary Production (MOD 17) [Online]. NASA. Available: http://modis.gsfc.nasa.gov/data/dataprod/nontech/MOD17.php [Accessed 17 January 2012 2012].

[26] Running, S.W., Nemani, R.R., Heinsch, F.A., Zhao, M., Reeves, M., Hashimoto, H. (2004): A continuous satellite-derived measure of global terrestrial primary production BioScience 54: 547 - 560

[27] Savill, P.S., Perrins, C.M., Kirby, K.J., Fisher, N. (eds.) (2010): Wytham Woods Oxford's Ecological Laboratory - Oxford: Oxford University Press.

[28] Sellers, P.J., Berry, J.A., Collatz, G.J., Field, C.B., Hall, F.G. (1992): Canopy reflectance, photosynthesis, and transpiration. III. A reanalysis using improved leaf models and a new canopy integration scheme - Remote Sensing of Environment 42: 187-216.

[29] Thomas, M.V., Malhi, Y., Fenn, K.M., Fisher, J.B., Morecroft, M.D., R., L.C., E., T.M. \& D, M.D. (2010): Carbon dioxide fuxes over an ancient broadleaved deciduous woodland in southern England - Biogeosciences Discussions 7: 3765 - 3814.

[30] Tucker, C.J. (1979): Red and photographic infrared linear combinations for monitoring vegetation - Remote Sensing of Environment 8: 127-150.

[31] Turner, M.G., Gardner, R.H., O'neill, R.V. (2002): Landscape Ecology in Theory and Practice: Pattern and Process - New York, Springer. 
[32] Uk-Ecn. 2012. Site Information: Wytham [Online]. UK Environmental Change Network. Available: http://www.ecn.ac.uk/sites/site/terr/wytham [Accessed 01 January 2012 2012].

[33] Wilson, R.T., Milton, E.J., Nield, J.M.(2012): Spatial variability of the atmosphere across southern England and the resulting error in assuming a uniform atmospheric correction. In: Remote Sensing and Photogrammetry Society Conference 2012, 12 - 14 Sep. 2012 University of Greenwich, London, GB.

[34] Wylie, B.K., Johnson, D.A., Laca, E., Saliendra, N.Z., Gilmanov, T.G., Reed, B.C., Tieszen, L.L., Worstell, B.B. (2003): Calibration of remotely sensed, coarse resolution NDVI to CO2 fluxes in a sagebrush-steppe ecosystem - Remote Sensing of Environment 85: 243-255.

[35] Xiao, J., Chen, J., Davis, K.J., Reichstein, M. (2012): Advances in upscaling of eddy covariance measurements of carbon and water fluxes. - Journal of Geophysical Research: Biogeosciences, 117, n/a-n/a.

[36] Xiao, J., Davis, K.J., Urban, N.M., Keller, K., Saliendra, N.Z. (2011): Upscaling carbon fluxes from towers to the regional scale: Influence of parameter variability and land cover representation on regional flux estimates - Journal of Geophysical Research: Biogeosciences 116: 1-15.

[37] Zar, J.H. (2010): Biostatistical Analysis, United State of America Pearson Education International. 